\title{
Morphine's interoceptive stimuli as cues for the development of associative morphine tolerance in the rat
}

\author{
ANTONIO CEPEDA-BENITO and PAUL SHORT \\ Texas A\&M University, College Station, Texas
}

\begin{abstract}
This study examined the extent to which a $4-\mathrm{mg} / \mathrm{kg}$ dose of morphine paired explicitly with a 12$\mathrm{mg} / \mathrm{kg}$ dose could gain associative control over tolerance development in rats. The analgesic effects of morphine were measured on the tail-flick test. Tolerance was defined as the dose shift to the right of the dose-response curve (DRC) of drug-experience animals relative to saline control animals. DRC shifts to the right were greater in the explicitly paired than in the explicitly unpaired animals. The results suggest that the pharmacological effects of morphine may function as a conditioned stimulus for the development of associative morphine tolerance.
\end{abstract}

Classical conditioning or associative accounts of drug tolerance explain that a distinctive context routinely paired with the administration of a drug (unconditioned stimulus, US) can become a conditioned stimulus (CS) that elicits a conditioned response (CR) measured as tolerance to the drug's effects (Baker \& Tiffany, 1985; Goudie \& Demellweek, 1986; Poulos \& Cappell, 1991). Animals receiving morphine in a distinctive test context display considerably more tolerance than do animals receiving morphine in their home cage environment (e.g., CepedaBenito \& Tiffany, 1992, 1995, 1996a, 1996b; Tiffany, Drobes, \& Cepeda-Benito, 1992; Tiffany, Maude-Griffin, \& Drobes, 1991).

Nonassociative tolerance can be distinguished from associative tolerance on the basis of features other than an absence of environmental specificity. For example, unlike nonassociative tolerance, associative tolerance does not dissipate rapidly after the cessation of drug delivery, and its development is facilitated by long interdose intervals (IDIs) in drug administration (see Baker \& Tiffany, 1985; Carter \& Tiffany, 1996; Poulos \& Cappell, 1991; Siegel, 1989).

Although exteroceptive stimuli have been used as the $\mathrm{CSs}$ in all demonstrations of associative morphine tolerance to date, there is also evidence that interoceptive stimuli may serve as effective CSs in the development of associative drug tolerance. For example, magnetic fields can act as CSs for the acquisition of associative tolerance to morphine's analgesic effects (Kavaliers \& Ossenkopp,

Funds for this research were provided by Grant S\&C $95-09$ from the Texas A\&M University Office of the VPRAP for Graduate Studies awarded to A. C.-B. We thank Mike Luebbert, Cara Campbell, Kerry A. McMahon, Sherry R. Overstreet, J. Gregory Ryan, and Bernadette F. Yllana for their help in conducting the experiment. Correspondence should be addressed to A. Cepeda-Benito, Department of Psychology, Texas A\&M University, College Station, TX 77843-4235 (e-mail: acb@tamu.edu).
1985). Others have shown that pharmacologically generated cues can subserve associative tolerance (Greeley, Lê, Poulos, \& Cappell, 1984). Greeley et al. reported that a low dose of ethanol that reliably preceded a high dose of ethanol could become a CS for the production of associative tolerance to ethanol's hypothermic effects. This finding lends some support to the suggestion that, in the absence of exteroceptive CSs, the initial interoceptive effects of a drug's administration may act as a CS for the development of associative tolerance to the same drug (see also Greeley \& Ryan, 1995; Grisel, Wiertelak, Watkins, \& Maier, 1994; Poulos, Hunt, \& Cappell, 1988; Siegel, 1989; Walter \& Riccio, 1983).

Whereas morphine can function as a discriminative stimulus for operant learning (see, e.g., Colpaert, 1978), there has been little research to examine the effectiveness of morphine as a pharmacological cue in the development of associative morphine tolerance. Recently, CepedaBenito \& Tiffany (1993) investigated whether a low dose of morphine could acquire associative control over the development of tolerance to a high morphine dose. Although their experimental design was similar to that of Greeley et al. (1984), Cepeda-Benito and Tiffany did not find support for the hypothesis that a small morphine dose administered exactly 60 min prior to a large morphine dose gained associative control over the expression of associative morphine tolerance.

In the present study, we examined whether morphine's interoceptive stimuli can function as CSs able to control associative, morphine tolerance effects. We made several methodological adjustments to improve the design used by Cepeda-Benito and Tiffany (1993). The changes were made according to principles of associative learning theory and empirical results of associative tolerance studies. First, the interval separating the low and high morphine doses was reduced from 60 to $30 \mathrm{~min}$. Second, the small dose used in this study $(4 \mathrm{mg} / \mathrm{kg}$ ) was greater than the small doses $(1.25$ and $2.5 \mathrm{mg} / \mathrm{kg}$ ) used by Cepeda- 
Benito and Tiffany (1993). These two variations were intended to ensure that drug effects from the small dose of morphine were still present when the large dose was administered. In research showing associative morphine tolerance effects, delayed rather than trace conditioning procedures have been used (e.g., Cepeda-Benito \& Tiffany, 1992, 1995, 1996a, 1996b). Cepeda-Benito and Tiffany (1993) may have used a trace conditioning design, because the salient drug effects of the 1.25- and a 2.5$\mathrm{mg} / \mathrm{kg}$ morphine doses could have dissipated, or could have been considerably weakened, by the time the large dose was administered 60 min later.

Third, we increased the overall nonreinforced (saline) to reintorced (morphine) injection ratio in order to prevent injections and handling cues from gaining associative control over morphine tolerance. Extensive exposure to saline injections before, during, and after the tolerance development phase should decrease the value of injection cues as CSs for the development of associative morphine tolerance (Cepeda-Benito \& Tiffany, 1995; Dafters \& Bach, 1985; Siegel, 1977, 1978).

Fourth and last, owing to the findings of Cepeda-Benito and Tiffany (1992) and Dafters and Odber (1989, Experiment 2), the number of low-high dose pairings was changed from 14 to 4 . Cepeda-Benito and Tiffany (1992) found that although unpaired animals did not start to show morphine tolerance effects until after 5 morphine administrations, differences between CS-US paired animals and CS-US unpaired animals were greater after 5 than after $1,3,8,14$, or 30 morphine injections. Similarly, Dafters and Odber found that the development of morphine tolerance was faster when rats were injected in the presence than in the absence of drug-predictive signals. These authors also found that tolerance differences between paired and unpaired animals could be detected from the second to the sixth conditioning session, but not thereafter. Together, these results suggest that morphine tolerance differences between paired and unpaired groups may be easier to detect after four or five than after more drug administrations.

\section{EXPERIMENT 1}

\footnotetext{
Method

Subjects. The subjects, 117 male Holtzman rats (Harlan, IN), 100-104 days old on their tolerance testing day, were housed individually in cages under a 12:12-h light/dark cycle. All experimental procedures took place during the light cycle.

Drugs and analgesia assessment. The low dose used as a cue for the delivery of a $12-\mathrm{mg} / \mathrm{kg}$ dose of morphine was $4 \mathrm{mg} / \mathrm{kg}$. The tolerance test doses were $0.75,1,2,4,6,8,10$, and $12 \mathrm{mg} / \mathrm{kg}$. All doses of morphine sulfate (expressed as the salt) were dissolved in saline with the concentration of sodium chloride adjusted so that the salinity of all final solutions was the same as physiological saline. Solutions of morphine and saline were injected subcutaneously in the scruff of the neck in a volume of $1 \mathrm{ml} / \mathrm{kg}$. Analgesia was assessed by the tail-flick method, which measures the latency for the rat to move its tail away from a hot beam of light (see, e.g., Tiffany et al., 1992; Tiffany et al., 1991). The rat was restrained by hand, and its tail was placed in a grooved plate so that the tail was under the light source. When the rat moved its tail from
}

the light beam, a photo sensitive cell tripped a timer and the tailflick latency was automatically recorded. To avoid interactions between tail area stimulated and degree of analgesia (Yoburn, Morales, Kelly, \& Inturrisi, 1984), each assessment consisted of the average of three consecutive trials, with the location of the beam varied systematically among the proximal, middle, and distal third of the rat's tail. The beam intensity was adjusted so that nondrugged animals flicked at approximately $4 \mathrm{sec}$. A $15-\mathrm{sec}$ limit was used to prevent damage to the tail.

Preexposure phase. In order to habituate the animals to the experimental procedures, all subjects were weighed once daily for 3 days and then were weighed once and injected twice with saline everyday for 7 days. All injections were given in pairs. The interinjection interval within each pair was $30 \mathrm{~min}$, and the interinjection interval between pairs averaged $24 \mathrm{~h}$ (range, 20-28 h). During the preexposure phase, the animals were also given daily exposures to mock tail-flick procedures. Mock tail-flicks consisted of placing each animal on the tail-flick device and activating the tail-flick apparatus for three consecutive 15 -sec trials; the animal's tail was placed away from the heat source. All injection pairs took place between the 2 nd and 7 th hour of the light cycle. Mock tail-flick exposures were conducted within the last $2 \mathrm{~h}$ of the light cycle.

Tolerance development phase. All subjects continued to receive a daily pair of injections during this phase. As in the preexposure phase, the within- and between-pair intervals were $30 \mathrm{~min}$ and $24 \mathrm{~h}$ (range, 20-28 h), respectively. The animals were randomly assigned to three conditions: explicitly paired (EP; $n=36$ ), explicitly unpaired (EU; $n=35$ ), and saline control ( $\mathrm{SC} ; n=44)$. All animals were equated on number of injection pairs; $E P$ and UP rats were also equated on number of low and high morphine doses, and on number of saline injections. EP animals received four morphinemorphine paired sessions, $96 \mathrm{~h}$ apart. For each morphine-morphine paired session, EP animals were injected, first, with a $4-\mathrm{mg} / \mathrm{kg}$ morphine dose, and, $30 \mathrm{~min}$ later, with a $12-\mathrm{mg} / \mathrm{kg}$ dose. In contrast, EU animals were injected, first, with a $4-\mathrm{mg} / \mathrm{kg}$ morphine dose, and, $30 \mathrm{~min}$ later, with saline. These animals received a saline injection, followed by a $12-\mathrm{mg} / \mathrm{kg}$ morphine dose the next day. There were six additional saline-saline paired sessions after the last morphine-morphine paired session. All animals had a series of mock tail-flick trials on nonmorphine days.

Test session. Testing took place the 7 th day after the last morphinemorphine paired session. On the test day, each animal received a pair of morphine injections $30 \mathrm{~min}$ apart and was tested on the tailflick $30 \mathrm{~min}$ after the second injection. The first injection was a 4$\mathrm{mg} / \mathrm{kg}$ dose of morphine for all animals. In order to construct doseresponse curves (DRCs), the second injection was one of four morphine doses randomly assigned to rats within each condition (8-11 animals per dose; see Figure 1).

Data analysis. The data from the three trials of each tail-flick assessment were averaged to produce a mean tail-flick latency for each animal, which was then transformed to a logarithmic scale. Factorial analyses may be analyzed through regression analyses by regressing the dependent variable on a set of coded vectors representing the main effects and interactions (Cohen \& Cohen, 1975). The data were subjected to two hierarchical multiple regression analyses (BMPD: 2PR software). Tail-flick latencies were regressed on morphine log dose level, group condition code, and the interaction (product) of these two variables. The variables were entered into the regression equation in three blocks in the order listed. One regression analysis compared SC and EU animals; the second analysis compared EU and EP rats. Statistically significant group effects occurred when the group condition variable contributed to predict tail-flick latencies above and beyond the variance accounted for by log dose level. Significant interactions would have occurred if the regression lines predicting each of the group's tailflick latencies had had different slopes; that is, the DRCs of the two groups would have been nonparallel. 


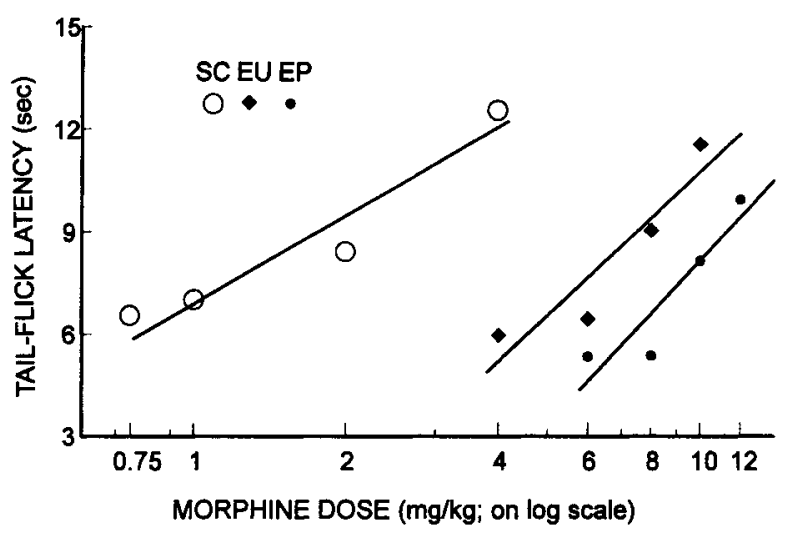

Figure 1. Mean tail-flick latency on the test session, as a function of morphine dose for each of the treatment conditions. The straight lines represent the best fitting lines for each condition, with tail-flick latency regressed on log morphine dose. For each of four conditioning sessions, explicitly paired (EP) rats received $4-\mathrm{mg} / \mathrm{kg}$ followed by a 12-mg/kg morphine dose. Explicitly unpaired (EU) subjects also received four 4-mg/kg morphine doses, but each of these injections was followed by a saline injection. $E U$ rats were injected with saline followed by a 12-mg/kg morphine dose $24 \mathrm{~h}$ after receiving a $4 \mathrm{mg} / \mathrm{kg}$ morphine dose. All injections consisted of saline for saline control (SC) animals. On testing day, all animals received a $4-\mathrm{mg} / \mathrm{kg}$ morphine dose followed by one of several morphine doses.

\section{Results}

The average tail-flick latencies for the three treatment conditions are shown in Figure 1. The straight lines for each condition represent the best fitting line calculated with tail-flick latency regressed on log dose of morphine. The DRC of EU rats was shifted significantly to the right of SC animals $\left[s R^{2}=.199, F(1,78)=22.08, p<.001\right]$. The DRC of EP animals was shifted significantly to the right of EU animals $\left[s R^{2}=.108, F(1,70)=9.63, p<\right.$ $.001]$. All DRC shifts were parallel, as is indicated by the absence of significant dose $\times$ group interactions $(F \mathrm{~s}<1.21)$.

The results indicate that administering a small and a large morphine dose explicitly paired produced larger tolerance effects than did giving the two doses explicitly unpaired. These results are consistent with the hypothesis that interoceptive stimuli from a small morphine dose may be used to predict the delivery of a larger dose and, thus, facilitate the development of associative tolerance effects.

Alternatively, the tolerance differences between the EP and EU animals might have been the result of conditioning the EP animals with a higher cumulative dose of morphine. That is, whereas the EP animals received a cumulative dosage of $16 \mathrm{mg} / \mathrm{kg}(4+12=16 \mathrm{mg} / \mathrm{kg})$ of morphine, the EU rats received $4 \mathrm{mg} / \mathrm{kg}$ of morphine one day and $12 \mathrm{mg} / \mathrm{kg}$ of morphine the following day.

\section{EXPERIMENT 2}

In this experiment, we investigated whether the results obtained in Experiment 1 were due to associative learning effects or to differential cumulative dosing effects. To equate cumulative dosing across groups, we compared the morphine tolerance levels of rats that received five pairings of a $4-\mathrm{mg} / \mathrm{kg}$ and a $12-\mathrm{mg} / \mathrm{kg}$ morphine dose (EP rats) with the tolerance levels of rats that received five pairings of saline and a $16-\mathrm{mg} / \mathrm{kg}$ morphine injection. The finding of greater tolerance effects in EP rats would support the notion that cumulative dosing did not play a significant role in the findings obtained in Experiment 1.

\section{Method}

Subjects. The subjects were 14 Holtzman male rats. These animals were of the same age as the rats in Experiment 1, and they were housed and maintained in the same manner.

Drugs, Procedure, and Analgesia assessment. The animals were randomly assigned to three conditions. The general procedures of the preexposure, tolerance development, and testing phases followed the design of Experiment 1. As in Experiment 1, the EP $(n=5)$ animals received a low dose of morphine $(4 \mathrm{mg} / \mathrm{kg})$ as a cue for the delivery of a $12-\mathrm{mg} / \mathrm{kg}$ dose of morphine. On the same days on which the EP animals were injected with morphine, the cumulative dose control (CDC; $n=4$ ) animals received a saline injection followed by a $16-\mathrm{mg} / \mathrm{kg}$ morphine injection. The SC animals $(n=5)$ received only saline. On nonmorphine days, the EP, $\mathrm{CDC}$, and $\mathrm{SC}$ animals received the same treatment (see Experiment 1 ).

On testing day, all animals received a $4-\mathrm{mg} / \mathrm{kg}$ morphine dose, followed by an $8-\mathrm{mg} / \mathrm{kg}$ morphine dose $30 \mathrm{~min}$ later. Tail-flick tests took place $30 \mathrm{~min}$ after the second injection.

\section{Results}

An analysis of variance yielded a significant overall effect $[F(2,11)=17.17, p<.001]$. Two a priori, directional hypotheses were tested using one-tailed $t$ tests for independent samples. The CDC rats had developed morphine tolerance, as was indicated by their lower tail-flick latencies $(M=9.73, S D=4.43)$ than those of the SC animals $[M=14.74, S D=.58 ; t(7)=2.44, p<.05]$. As hypothesized, the EP rats had developed more morphine tolerance than had the CDC animals. That is, the EP rats displayed lower tail-flick latencies $(M=4.87, S D=$ 1.77), than did the CDC animals $[t(7)=2.19, p<.05]$.

\section{DISCUSSION}

The data show that animals that were injected with morphine during the tolerance development phase were more tolerant to morphine's analgesic effects than animals receiving morphine for the first time during testing. This was indicated by the lower tail-flick latencies observed in the EP, EU, and CDC animals as opposed to the SC animals. The data also revealed that animals receiving a small dose of morphine explicitly paired with a large dose were more tolerant than animals that received the two doses unpaired (EU rats) and than animals that received a comparable dose given in a single cumulative injection (CDC rats). The results appear to be congruent with the hypothesis that a small dose of morphine may function as a CS capable of eliciting associative tolerance effects in anticipation of larger morphine effects (see Siegel, 1989). 
It could be reasoned that the small morphine dose acquired the properties of a conditioned inhibitor (CS-) in EU rats because of its negative contingency with the delivery of the high morphine dose (Fanselow \& German, 1982; Siegel, Hinson, \& Krank, 1981). In the negative US-CS contingency procedure for inhibitory conditioning, the US is never paired with a distinctive stimulus, and the probability that the US will occur is greater when the CS - is absent than when it is present (see LoLordo \& Fairless, 1985). For the EU animals, the $12-\mathrm{mg} / \mathrm{kg}$ dose was not paired with a distinctive cue, and its delivery was never immediately preceded by the $4-\mathrm{mg} / \mathrm{kg}$ morphine dose. The interpretation that the small dose of morphine could have been a CS - for EU rats is still consistent with the hypothesis that a small morphine dose can serve as a $\mathrm{CS}$ within an associative morphine tolerance paradigm.

The present results are important because they suggest that the potential associative value of pharmacological stimuli may have been underestimated in past research. It is generally believed that the necessary and sufficient condition for the development of associative morphine tolerance consists in the administration of morphine contingent with a CS at sufficiently long IDIs (see Poulos \& Cappell, 1991). Our results suggest that a small morphine dose may serve as a CS for associative morphine tolerance. These results give some credibility to the hypothesis that the initial pharmacological effects of a morphine dose may serve as a CS announcing the peak effects (or US) of the same dose (Grisel et al., 1994; Siegel, 1989; Walter \& Riccio, 1983). Thus, it is possible that the most critical condition for the development of associative morphine tolerance is simply the administration of morphine at sufficiently long IDIs. That is, if the initial effects of a morphine dose can serve as the CS for the same dose's peak effects, the necessary CS-US contingency is inherently present during each drug administration (see also Grisel et al., 1994).

There have been suggestions indicating that failures to find evidence of contextual drug tolerance may have been due to overshadowing of external drug cues by the interoceptive stimuli of the drug dose itself (e.g., Grisel et al. 1994; Walter \& Riccio, 1983). Some have gone as far as to propose that maybe it is not even necessary to make a distinction between two "kinds" of tolerance (associative and nonassociative), because what we call nonassociative or "pharmacological" tolerance might just be associative tolerance that is supported by internal rather than external stimuli (see Walter \& Riccio, 1983, p. 661). Although we defend the position that interoceptive drug stimuli may play a role as a CS, by itself or as part of a complex CS made out of external and internal cues, we still believe that associative morphine tolerance and nonassociative morphine tolerance are controlled by different underlying mechanisms. It would be difficult to conceptualize nonassociative tolerance as a $\mathrm{CR}$, because, unlike tolerance associatively supported by external stimuli, nonassociative tolerance dissipates rapidly after the cessation of drug delivery (see, e.g., Tiffany et al., 1992). If interoceptive drug cues could overshadow ex- ternal drug cues, and if pharmacological tolerance were a CR elicited by interoceptive drug cues, there would then be no reason to predict greater transiency for noncontextual than for contextual tolerance.

Other data also support the notion that associative and nonassociative tolerance are controlled by different underlying mechanisms. For example, Carter and Tiffany (1996) examined the cross-tolerance profiles of associative and nonassociative morphine tolerance and analgesia produced by mu and kappa agonists. Associative and nonassociative morphine-tolerant animals were tested for tolerance to fentanyl, a mu-specific agonist like morphine, and U50-488, a kappa-specific agonist. The results of this study were that noncontextual or pharmacological tolerance was cross-tolerant with fentanyl but not U50-488. That is, pharmacological tolerance was receptor specific. Conversely, contextual or associative morphine tolerance was cross-tolerant with both fentanyl and U50-488. That is, associative morphine tolerance lacked receptor specificity.

The finding that a small dose may serve as a CS for associative morphine tolerance may also have practical implications. It has been suggested that repeated exposure to drug cues in the absence of drug use will result in the extinction of the CRs presumed to underlie the experience of drug cravings (see Childress, McLellan, \& O'Brien, 1986; Greeley \& Ryan, 1995). This approach presumes that the risk of relapse should be reduced by extinguishing a precursor of drug use-namely, cue-elicited craving. The present results are relevant to the extent that pharmacological cues may be part of the CS complex responsible for conditioned cravings. That is, cue exposure treatments could be used to study the merits of including a small drug dose as part of the CS complex. Extinction of cue-elicited cravings should be more effective the closer the unreinforced cue exposure manipulation replicates the actual craving eliciting CS (Childress et al., 1986). The inclusion of small drug doses during cue exposure treatments may better reproduce the CSs responsible for conditioned craving.

The interpretation of our findings should consider the range of conditions within which they might be replicated. Cepeda-Benito and Tiffany (1993) found no evidence that low doses of morphine paired with a high dose acquired associative control over tolerance. That is, they found that both EP and EU animals developed similar levels of morphine tolerance. Although these authors did not pair morphine delivery with a distinctive context, they concluded that the tolerance obtained in their study was a conditioned form of tolerance. Cepeda-Benito and Tiffany (1993) speculated that handling and injection cues were the CS complex controlling associative morphine tolerance in both groups of rats. In our investigation, we maximized the possibility of detecting differences between the EP and EU groups by (1) minimizing the role of injection cues as potential CSs, (2) assuring a trace (as opposed to a delay) conditioning procedure, and (3) testing the rats after four conditioning sessions, when the likelihood of detecting differences between CS-US 
paired and CS-US unpaired animals is presumably the highest (see the Introduction for a detailed discussion of these changes). The extent to which each of these specific methodological changes substantively contributed to the present results can be clarified only with extensive research. In future investigations, the length of the interdose pairing interval, the morphine concentration of the small and large morphine doses, and the number of conditioning sessions should be varied systematically.

\section{REFERENCES}

BAKER, T. B., \& TiffaNY, S. T. (1985). Morphine tolerance as habituation. Psychological Review, 92, 78-108.

Carter, B. L., \& Tiffany, S. T. (1996). Cross-tolerance of associative and nonassociative morphine tolerance in the rat with mu- and kappa-specific opioids. Psychopharmacology, 123, 289-296.

Cepeda-Benito, A., \& Tiffany, S. T. (1992). Effect of number of conditioning sessions on the development of associative tolerance to morphine. Psychopharmacology, 109, 172-176.

Cepeda-Benito, A., \& Tiffany, S. T. (1993). Morphine as a cue in associative tolerance to morphine's analgesic effects. Pharmacology, Biochemistry \& Behavior, 46, 149-152.

Cepeda-Benito, A., \& Tiffany, S. T. (1995). Role of drug-administration cues in the associative control of morphine tolerance in the rat. Psychopharmacology, 122, 312-316.

Cepeda-Benito, A., \& Tiffany, S. T. (1996a). The failure of noncontingent morphine exposure to disrupt context-specific morphine tolerance. Pharmacology, Biochemistry \& Behavior, 54, 557-580.

Cepeda-Benito, A., \& Tiffany, S. T. (1996b). Test-specific manifestations of associative tolerance to the analgesic effects of morphine in the rat. Psychobiology, 24, 327-332.

Childress, A. R., Mclellan, A. T., \& O'Brien, C. P. (1986). Conditioned responses in a methadone population: A comparison of laboratory, clinic, and natural settings. Journal of Substance Abuse Treatment, 3, 173-179.

Cohen, J., \& Cohen, P. (1975). Applied multiple regression/correlational analysis for the behavioral sciences. Hillside, NJ: Erlbaum.

COLPAERT, F. C. (1978). Discriminative stimulus properties of narcotic analgesic drugs. Pharmacology, Biochemistry \& Behavior, 9, 863887.

DAFTERS, R. I., \& BACH, L. (1985). Absence of environment-specificity in morphine tolerance acquired in nondistinctive environments: Habituation or stimulus overshadowing? Psychopharmacology, 87, 101-106.

DAFTERS, R. I., \& ODBER, J. (1989). Effects of dose, interdose interval and drug-signal parameters on morphine analgesic tolerance: Implications for current theories of tolerance. Behavioral Neuroscience, 103, 1082-1090.

FANSELOW, M. S., \& German, C. (1982). Explicitly unpaired delivery of morphine and the test situation: Extinction and retardation of tolerance to the suppressing effects of morphine on locomotor activity. Behavioral \& Neural Biology, 35, 231-241.

Goudie, A. J., \& DEmellweEK, C. (1986). Conditioning factors in drug tolerance. In S. R. Goldberg \& I. P. Stolerman (Eds.), Behav- ioral analysis of drug dependence (pp. 225-285). New York: Academic Press.

Greeley, J., LÊ, D. A., Poulos, C. X., \& CAPPell, H. (1984). Alcohol is an effective cue in the conditional control of tolerance to alcohol. Psychopharmacology, 83, 159-162.

GREeLEY, J., \& RYAN, C. (1995). The role of interoceptive cues for drug delivery in conditioning models of drug dependence. In D. C. Drummond, S. T. Tiffany, S. Glautier, \& B. Remington (Eds.), Addictive behaviour: Cue exposure theory and practice (pp. 119-136). Chichester, U.K.: Wiley.

Grisel, J. E., Wiertelak, E. P., Watkins, L. R., \& Maier, S. F. (1994). Route of morphine administration modulates conditioned analgesic tolerance and hyperalgesia. Pharmacology, Biochemistry \& Behavior, 49, 1029-1035.

KaVAliERS, M., \& OSSENKopP, K. (1985). Tolerance to morphineinduced analgesia in mice: Magnetic fields function as environmental specific cues and reduce tolerance development. Life Sciences, 37, 1125-1135.

LOLORDO, V. M., \& FaIRLESS, J. L. (1985). Pavlovian conditioned inhibition: The literature since 1969. In R. R. Miller \& N. E. Spear (Eds.), Information processing in animals: Conditioned inhibition (pp. 1-50). Hillsdale, NJ: Erlbaum.

Poulos, C. X., \& CAPPell, H. (1991). Homeostatic theory of drug tolerance: A general model of physiological adaptation. Psychological Review, 98, 390-408.

Poulos, C. X., Hunt, T., \& Cappell, H. (1988). Tolerance to morphine analgesia is reduced by the novel addition or omission of an alcohol cue. Psychopharmacology, 94, 412-416.

SIEGEL, S. (1977). Morphine tolerance acquisition as an associative process. Journal of Experimental Psychology: Animal Behavior Processes, 3, 1-13.

SIEGEL, S. (1978). Tolerance to the hyperthermic effect of morphine in the rat is a learned response. Journal of Comparative \& Physiological Psychology, 92, 1137-1149.

SiEgel, S. (1989). Pharmacological conditioning and drug effects. In A. J. Goudie \& M. B. Emmet-Oglesby (Eds.), Psychoactive drugs: Tolerance and sensitization (pp. 115-180). Clifton, NJ: Humana.

Siegel, S., Hinson, R. E., \& Krank, M. D. (1981). Morphine-induced attenuation of morphine tolerance. Science, 212, 1533-1534.

Tiffany, S. T., Drobes, D. J., \& Cepeda-Benito, A. (1992). Contribution of associative and nonassociative processes to the development of morphine tolerance. Psychopharmacology, 109, 185-190.

Tiffany, S. T., Maude-Griffin, P. M., \& Drobes, D. (1991). The effect of dose interval on the development of associative tolerance to morphine in the rat: A dose response analysis. Behavioral Neuroscience, 102, 534-543.

WALTER, T. A., \& RICCIO, D. C. (1983). Overshadowing effects in stimulus control of morphine analgesic tolerance. Behavioral Neuroscience, 97, 658-662.

Yoburn, B. C., Morales, R., Kelly, D. D., \& INTURRISI, E. C. (1984). Constraints on the tail-flick assay: Morphine analgesia and tolerance are dependent upon locus of tail stimulation. Life Sciences, 34, $1755-1762$.

(Manuscript received August 28, 1996; revision accepted for publication April 7, 1997.) 